DOI - https://doi.org/10.5965/2316796309172020163

\title{
Ergonomia, design e gamificação como instrumentos para a educação
}

\section{Ergonomics, design and gamification as instruments for education}

César Augusto Domingos Filho ${ }^{1}$

Marcelo Egídio Brasileiro do Vale ${ }^{2}$

Tiago Barros Pontes e Silva ${ }^{3}$ Francisco George de Sousa Lopes ${ }^{4}$ 


\section{Resumo}

O estudo busca compreender e Thestudyaimstounderstandandtransform transformar a interação entre professor the interaction between teacher and e alunos no processo de aprendizagem students in the physics learning process de física na modalidade presencial of Youth and Adult Teaching (presential de Ensino de Jovens e Adultos. Para modality). Therefore, the ergonomics, tanto, foram adotadas as abordagens design and gamification approaches were de ergonomia, design e gamificação adopted to seek an inductive process of para buscar um processo indutivo de diagnosisandalsoasolution that increases diagnóstico e também uma solução que the student's engagement. Consequently, amplie o engajamento dos estudantes. from the understanding of their context Portanto, a partir da compreensão do seu supports, constraints, motivations and contexto, suportes, constrangimentos, supports, constraints, motivations and contexto, suportes, constrangimentos, goals, structural solutions were conceived
motivações e metas, foram concebidas for the organization of the activities, as soluções estruturais para a organização well as their supports in analog and digita das atividades, assim como seus suportes interfaces. By adopting an approach that em interfaces analógicas e digitais. Ao se considers the complexity of reality at adotar uma abordagem que considere a the design activity, there was a greater complexidade da realidade na atividade adherence of the designed solutions, projetual, constatou-se uma maior demonstrating its potential for social aderência das soluções concebidas, transformation, capable of connecting demonstrando 0 seu potencial de individuals more significantly.

transformação social, capaz de conectar indivíduos de maneira mais significativa.

Palavras-chave: ergonomia, design, gamificação, educação, aprendizagem

\section{Introdução}

Em um mundo pós-revolução digital pode-se constatar o impacto da velocidade da informação de diversas maneiras. Um olhar despercebido sobre tais fatos pode criar a impressão de que a sociedade chegou no auge de seu desenvolvimento para a educação, desenvolvendo estratégias como crowdlearning, aprendizado baseado em jogos e ensino a distância. Entretanto, ao analisar o ensino tradicional, o Brasil possui uma taxa de reprovação de $12 \%$ para o ensino médio (INEP, 2016), o que corresponde a mais de 906 mil jovens e adolescentes. Pode-se constatar, a partir dessa perspectiva, que a revolução digital conferiu avanços pouco significativos para o ensino médio tradicional, uma vez que, em 1997, a taxa de reprovação era de 11,4\%. O modelo cartesiano de ensino nas escolas tradicionais tem se tornado pouco engajador para as novas gerações, acostumadas com a velocidade da informação do mundo contemporâneo.

Como um movimento a favor do ensino, novas soluções têm se mostrado necessárias para promover diversão e facilidade de entendimento para as novas gerações, aliando a curva de aprendizado à de aquisição de conhecimento dos estudantes. Este mesmo fenômeno é recorrente no contexto dos jogos, nos quais o nível de dificuldade deve ser progressivo para compensar o aprendizado sobre como jogar, mantendo-se o foco de atenção dos jogadores. Este efeito é descrito pela Teoria do Fluxo, proposta por Csikszentmihalyi (1990), adaptado para o contexto dos jogos por Chen (2006). Enxergando o problema como oportunidade, novas estratégias vêm surgindo para mitigar os dados negativos. Dentre as mais inovadoras está a gamificação, que é a utilização de elementos de jogos dentro de contextos não-lúdicos para atingir um objetivo específico, promovendo um maior engajamento com a atividades de aprendizagem (FADEL et al, 2014).

Neste sentido, o trabalho apresentado consiste no desafio de investigar uma abordagem de projeto inspirada na perspectiva ergonômica que promova uma nova experiência para as aulas de física de $2^{\circ}$ ano do ensino médio dentro do contexto de Ensino de Jovens e Adultos (EJA). Além de um processo centrado nos alunos, o projeto Ensino de Jovens e Adultos (EJA). Além de um processo centrado nos alunos, o projeto
visa integração de elementos oriundos da revolução digital à sala de aula e aumento de engajamento. O projeto foi desenvolvido nas salas de aula do Centro de Ensino 6 (CED 6) da Ceilândia, periferia de Brasília, Distrito Federal. A realização do projeto se deu nas quatro turmas de $2^{\circ}$ ano do ensino médio, totalizando cerca de 60 alunos com faixa etária variando entre 18 e 60 anos. Entende-se que um dos maiores desafios da proposta é tentar identificar uma solução que consiga abranger um espectro variado de idades e experiências, como demanda o contexto de EJA.

Para começar a solucioná-lo, definiu-se os seguintes objetivos específicos:

- Identificar os principais problemas dentro do processo didático para os

- Projetar uma solução gamificada que unifique os conteúdos didáticos com elementos de jogos para criar um formato mais atrativo para o ensino de

- Realizar uma reflexão inicial acerca da proposta, considerando a sua implementação e expectativa de resultados.

O presente relato se concentra em descrever as reflexões oriundas da adoção
${ }^{1}$ Designer, UNB (cesinhaobdc@gmail.com)

${ }^{3}$ Doutor em Arte, UNB (tiagobps@gmail.com)

${ }_{4}^{4}$ Mestre em Design, UNB (fgeorge28@gmail.com) alunos de EJA do CED 6; física;

ISSN: 2316-7963

Presente relato se concentra em descrever as 
de um pensamento de design para a redefinição das estratégias de aprendizagem do conteúdo de física para $\circ 2^{\circ}$ ano da EJA, inspirado pela natureza ascendente da abordagem ergonômica de compreensão e transformação da realidade. Portanto, as investigações mais detalhadas acerca das dificuldades de atualização da escola pública, assim como do campo do Design como perspectiva, evidenciando seus resultados preliminares, podem ser consultadas em (LOPES et al, 2019), a qual o presente estudo é filiado.

\section{Educação, aprendizagem e gamificação}

São frequentes as discussões a respeito de uma crise existente na educação atual, que consiste no descompasso entre a forma como os alunos estão acostumados aos padrões provenientes da revolução digital e o modelo de ensino tradicional, uma vez que este foi construído sob uma ótica industrial e seriada, opondo-se ao pensamento digital contemporâneo, dinâmico e não-linear (MATTOS, 2017). O Brasil não é uma exceção a essa realidade. A despeito do vasto acesso à informação adquirido pelos estudantes após a proliferação da Internet e, mais recentemente, dos dispositivos móveis, a taxa de reprovação nas escolas públicas continua praticamente a mesma desde 1997 (INEP, 2016). Mesmo com muitas tentativas de atualizar a sala de aula, há poucas evidências de um significativo impacto no modelo tradicional das escolas, sobretudo as escolas públicas.

Adiciona-se a esse cenário a dificuldade de adaptação do modelo de ensino aos estudantes, que são imersos em um contexto a cada dia mais contrastante com o das escolas. Assim, embora o trabalho prescrito pelas autoridades competentes que elaboram os currículos de ensino nacional seja bem executado, a prática da sala de aula fica a cargo dos professores, que nem sempre conseguem realizar a tradução necessária para os estudantes. Tendo em vista a problemática exposta, nota-se o surgimento de novas abordagens mais engajadoras ao mindset digital: jogos educativos, simuladores, jogos sérios (serious games) e aprendizagem baseada em jogos digitais. As aplicações destas abordagens podem ser realizadas em cenários de sala de aula, mas também em novos cenários, como corporativo ou até mesmo militar (PRENSKY, 2001).

Outra abordagem que vem transformando o modo tradicional de ensino é o PBL (Problem Based Learning), em tradução livre, aprendizagem baseada em problemas. Segundo Hmelo-silver e Barrows (2006), PBL é um método de aprendizagem ativo baseado no uso de situações-problema estruturadas como estímulo à aprendizagem. Tais situações não possuem necessariamente uma única resposta correta, mas requerem que os educandos considerem as possíveis variáveis que suportem a construção de uma solução. Este tipo de abordagem é frequentemente aplicado em sala de aula para extrair conteúdos teóricos dessas situações problemas.

Entretanto, todas as abordagens listadas possuem característica descendentes (top-down), ou seja, se originam a partir de atores com poder centralizado que precisam prever um cenário para depois estruturar o jogo, esperando que aquela aprendizagem específica aconteça. Quando se fala em um método ascendente (bottom-up), no qual primeiramente é analisada a realidade das pessoas envolvidas para se criar um jogo que atenda uma demanda particular, as soluções digitais se tornam caras e de difícil acesso tecnológico. Em contrapartida, as soluções analógicas se tornam pontuais, beirando a superficialidade.

Desta forma, abre-se espaço para uma abordagem que permite uma análise da motivação atual dos usuários do sistema, de tal forma a criar um processo ascendente que resulta em engajamento, diversão e aprendizagem de maneira acessível e mais significativa: a gamificação. Gamificação consiste na utilização de elementos e mecânicas de jogos em contextos não lúdicos com o intuito de engajar indivíduos a ação em prol de um objetivo estabelecido (KAPP et al, 2012). O presente estudo emprega o conceito como ferramenta que pode diminuir o contraste entre os pensamentos industrial, do ensino tradicional vigente, e digital, tendência presente nas sociedades contemporâneas.

Ao contrário dos outros métodos que empregam jogos em um sistema fechado, a abordagem da gamificação torna possível um delineamento ascendente, partindo do usuário para então se desenvolver no campo do jogo. Para melhor ilustrar esse contraste, foi proposta uma matriz $2 \times 2$ comparativa (Figura 1) entre a função (real ou lúdico) de algumas abordagens de jogos na educação e sua estrutura enquanto sistema (fechado ou aberto).

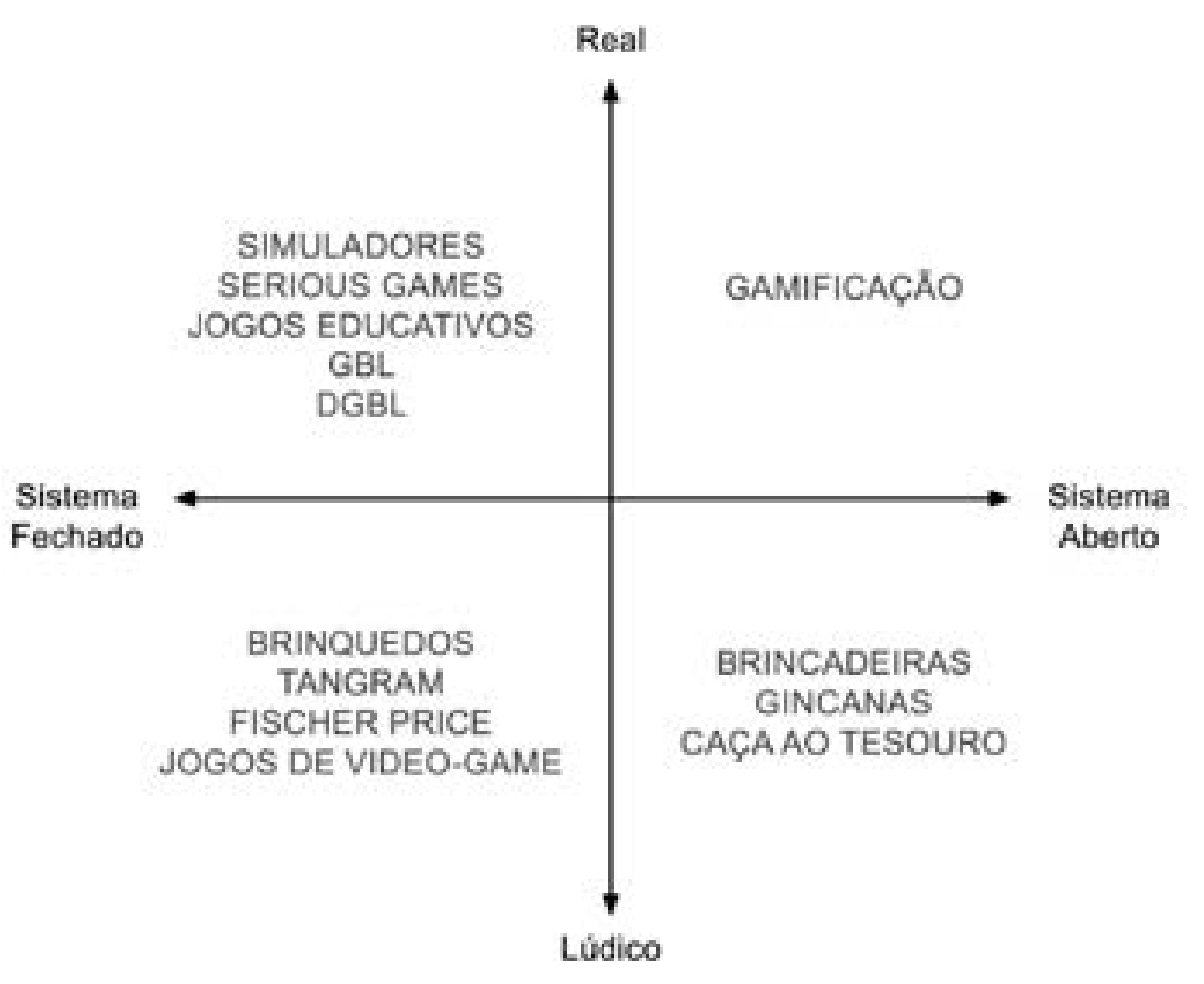

Figura 1: Matriz que compara função e estrutura das abordagens interativas.

Nos quadrantes inferiores, as abordagens citadas possuem função lúdica, isto é, com foco no entretenimento do usuário e não no seu processo de aprendizagem que quando existente, é considerado uma consequência da interação. A esquerda encontrase os sistemas fechados, como brinquedos e jogos de videogame. À direita encontram-se 
os sistemas abertos como brincadeiras e gincanas. Nos quadrantes superiores, constam as abordagens com função real, isto é, nas quais o foco principal é a aprendizagem. À esquerda encontra-se as abordagens de sistema fechado, ou seja, artefatos e jogos. A direita encontra-se a gamificação, que unifica elementos de jogos com contextos não lúdicos.

A gamificação é uma abordagem de estrutura aberta e função real e, portanto, é possível torná-la mais aderente ao contexto. Dan Saffer, 2010, afirma que para o design de interação social, qualquer tipo de artefato pode conectar pessoas. O uso da gamificação como instrumento de interação social permite que os designers criem sistemas interativos que facilitem a comunicação entre indivíduos por meio de elementos de jogos, considerando-se suas motivações para o engajamento.

\section{A abordagem ergonômica e o processo de Design}

O percurso metodológico adotado no presente estudo baseia-se em dois campos: a Análise Ergonômica do Trabalho (AET), de Guérin et al (2001); e o processo de resolução do problema de design, comumente desenhado por meio do diamante duplo (DESIGN COUNCIL, 2017), que será discutido adiante. O que se propõe com a inspiração nessas duas abordagensé a adoção de um repertório ascendente de produção do conhecimento que acople o diagnóstico produzido com processos interventivos voltados para a transformação social (BONSIEPE, 1997).

Especificamente, o que se espera é apresentar a perspectiva do design de interação, que projeta uma nova narrativa de interação entre os atores envolvidos, com os registros de estratégias operatórias levantados em campo, conforme sugere Silva (2009). Ainda, destaca-se o uso de parâmetros de gamificação como uma orientação para o levantamento das principais motivações dos atores envolvidos no diagnóstico.

\subsection{A Análise Ergonômica do Trabalho (AET)}

Segundo Abrahão et al (2009) e Guérin et al (2001), uma ação ergonômica comporta diversas fases, dentre as quais destaca-se para o presente estudo: análise da demanda, coleta de informações, observações globais e abertas da atividade e elaboração de um pré-diagnóstico. Assim, este primeiro momento enfatiza o uso de técnicas de pesquisa mais abertas e exploratórias, focando na flexibilidade procedimental como instrumento para garantir a aderência do conhecimento produzido ao contexto investigado.

A partir dessa perspectiva, a abordagem ergonômica busca a compreensão das dimensões prescritas para as situações investigadas, assim como a maneira na qual as atividades são realizadas de fato. Pela distinção entre a tarefa e a atividade, entende-se que são evidenciadas as principais dificuldades encontradas pelas pessoas envolvidas na atividade, assim como são reveladas as principais estratégias empregadas para contorna-las. Neste contexto, as dimensões física, cognitiva e afetiva de todos os atores envolvidos na atividade são considerados relevantes para o estudo.

Mais especificamente, sob a ótica da ergonomia cognitiva, são levantados os pontos-de-vista dos sujeitos que realizam a atividade, identificando-se as suas principais representações para ação, os traços significativos de experiências prévias evocados para se realizar a atividade (CAÑAS, ANTOLÍ \& QUESADA, 2001). A partir dessas representações, são concebidas as estratégias operatórias (SILVINO \& ABRAHÃO, 2003) para a realização da atividade, manifestadas no ambiente por comportamentos conhecidos como modos operatórios.

Portanto, a partir do levantamento dos modos operatórios dos sujeitos, assim como da identificação das suas principais representações para ação, é formulado o diagnóstico do contexto de estudo, no qual se procura compreender as principais demandas para intervenção, considerando-se a organização das tarefas e os suportes oferecidos para a sua realização (ABRAHÃO et al, 2009).

Para compreensão de todosessesfatores, durante toda a pesquisa foram realizadas visitas para observação da atividade de aula na escola, assim como entrevistas com os alunos e o professor da disciplina. Também foi conduzido um grupo focal composto por dois alunos de um total de 4 turmas, totalizando 8 alunos, pesquisas bibliográficas e reuniões de ideação, visando as propostas de novas configurações para a estratégia de ensino-aprendizagem vigente. O registro de todas essas informações observadas fo realizado empregando-se mapas mentais, que posteriormente resultaram nos requisitos de prototipação da gamificação.

Assim, foram levantadas as atribuições formais de todos os atores envolvidos no processo, como a escola de modo geral, coordenação, professores e alunos, os seus objetivos e suportes oferecidos para a realização das aulas, como o ambiente da escola e das salas de aula, as mesas e carteiras, a organização das atividades no tempo, os instrumentos disponíveis, como televisões e rede de Internet, assim como os comportamentos do professor e dos alunos em contexto de sala de aula, incluindo a frequência às aulas, posturas em sala de aula, envolvimento com as atividades, entre outras variáveis.

Apesar de ser inspirado em grande parte na AET, principalmente nas etapas iniciais do processo de aproximação com a escola, conforme as hipóteses de intervenção surgiam, foram prioritariamente tratadas como descrições de contexto, de tal forma que o processo foi gradualmente perdendo vínculos com as especificidades da AET e ganhando corpo enquanto projeto de design. Dessa maneira, a análise ergonômica serviu como método indutivo dos requisitos que serviram, em seguida, para a proposição da solução do problema de design.

Portanto, o que se espera é demonstrar a proposta de Silva (2009), que vincula o diagnóstico ergonômico manifestado no registro dos modos operatórios reais e prescritos com a proposição de uma nova narrativa de interação planejada para o contexto investigado, estabelecido a partir da abordagem propositiva do design de interação. Com isso, o processo de design enfatiza prioritariamente a dimensão estrutural do contexto estudado, configurando uma nova organização para a atividade. Posteriormente, a partir deste novo planejamento, são então concebidas as suas interfaces analógicas e digitais.

\subsection{Processo de Design}


Entende-se que o processo de design organiza e explora a maneira como as pessoas agem para transformar o mundo à sua volta (BONSIEPE, 2011), possuindo assim um caráter investigativo e propositivo simultaneamente (SILVA, 2015). Com isso, são frequentemente propostos como processos de compreensão e busca, conforme sugerido por Newell e Simon (1972). Enquanto atividade profissional, o Design adota um processo que visa a otimização da aderência da solução proposta ao contexto, enquanto potencializa a sua diferenciação das soluções pré-existentes, sua inovação.

Contudo, os problemas de natureza complexa frequentemente não apresentam uma única solução estanque e previsível, fazendo-se necessário, portanto, a estruturação do problema para mapear os requisitos que configuram as opções viáveis e válidas para o contexto estudado. Estas etapas possuem seus próprios ciclos de pensamentos divergentes e convergentes, voltados para a compreensão e busca no espaço do problema de design (SILVA, 2015; 2016). Assim, enquanto a análise ergonômica compreende o diagnóstico da situação, o design permite uma na ideação das soluções e a prototipação de um sistema aderente ao contexto, ilustrado pela Figura 2.

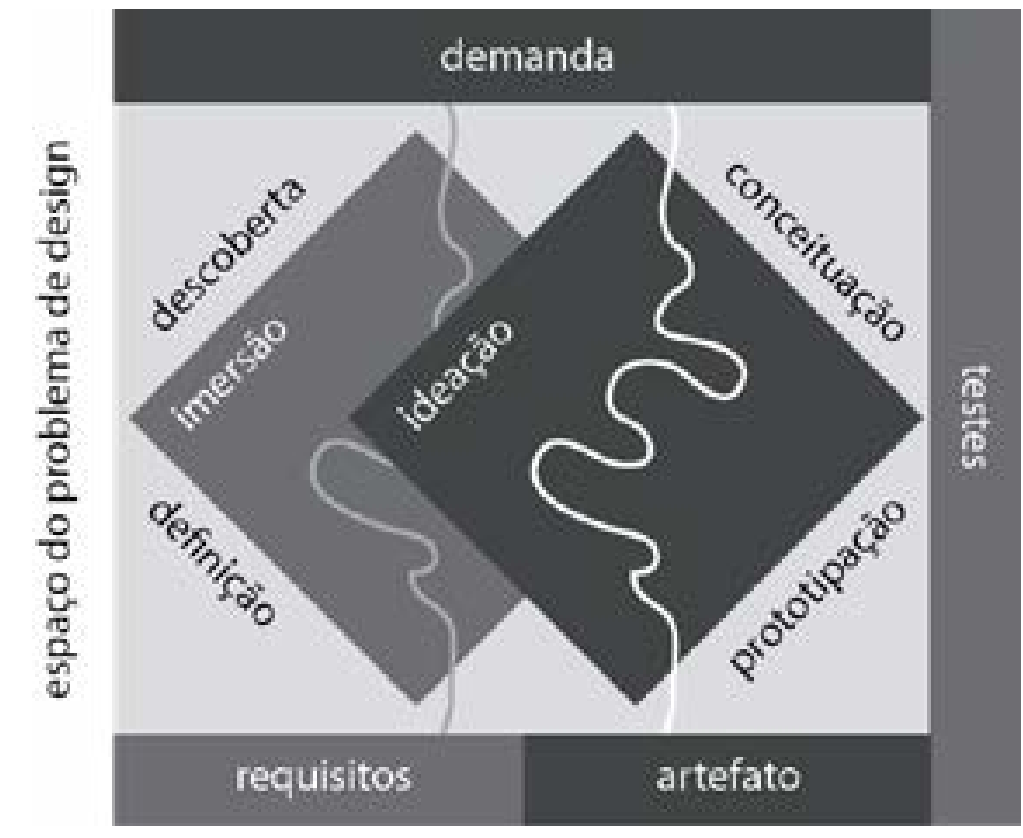

Figura 2: Representação visual dos dois ciclos de ações divergentes-convergentes do processo de design Retirado de Silva (2016)

A partir dessa proposta, a etapa de estruturação consiste em uma imersão dentro do espaço do problema de design, que inicia na descoberta da demanda, originando análises divergentes das variáveis pertinentes ao projeto, e que resultam na definição dos seus requisitos, obtidos pela síntese convergente dessas variáveis. Na investigação realizada no CED 06 de Ceilândia, esta fase de imersão foi justamente a que incorporou as etapas da AET. A utilização da AET como estratégia de estruturação do problema de design permitiu um entendimento real do contexto, de caráter imersivo, por meio de entrevistas não-estruturadas abertas, observações globais e observações participativas.
O caráter imersivo presente na etapa de pesquisa visa garantir que o sistema criado convirja para as necessidades reais dos alunos, caracterizando-se como design centrado no usuário (LOWDERMILK, 2013). No presente estudo, houve uma ênfase nos aspectos motivacionais dos alunos, considerando-se a abordagem de gamificação adotada, apresentados a seguir. A partir dos resultados das etapas de estruturação, o processo de ideação foi realizado, mais uma vez adotando os pensamentos divergentes e convergentes do design para a proposição de configurações nos níveis estruturais de interação e organização das atividades, assim como também para as superfícies gráficas das interfaces do sistema projetado, apresentados posteriormente enquanto resultados do presente relato.

\subsection{O levantamento das motivações}

Desenvolvida após 10 anos de estudos pelo autor e consultor Yu-kai Chou (2015), a Octalysis é uma ferramenta que possibilita uma análise voltada para o usuário de determinado sistema ou serviço. O autor sintetiza o comportamento decisório humano em oito motivadores universais, e associa-os a produtos gamificados, tornando viável a criação planejada de soluções engajadores e divertidas.

Os oito motivadores propostos pelo autor são (em tradução livre): significado épico e chamado; desenvolvimento e realização; empoderamento da criatividade e feedback; pertencimento e posse; influência relacionamento social; escassez e impaciência; imprevisibilidade e curiosidade; perda e evasão à perda. Esses motivadores de comportamento são distribuídos em uma estrutura octogonal, que se molda conforme a análise é desenvolvida, e busca mostrar ao projetista as lacunas de projeto e o foco para as mecânicas de motivação.

Seu objetivo é viabilizar uma estratégia aderente ao contexto e, para isso, é necessário conhecer que motivadores são mais relevantes para os usuários. Assim, ela serve como um mapa da relação entre as motivações do usuário e os elementos de jogos mais engajadores para esse público. Para chegar às informações necessárias para preencher a Octalysis, foi utilizada uma pesquisa estruturada realizada com o grupo focal realizada com 8 alunos. Para tanto, foi adotado um instrumento em formato de roteiro com perguntas para cada motivador, o que permitiu compreender o peso de cada motivador dentro da realidade dos alunos. As respostas foram registradas em um mapa mental que foi empregado posteriormente para fomentar a etapa de ideação do projeto.

\section{Resultados}

Os resultados foram organizados em dois grupos, voltados para a compreensão do próprio processo de design. Assim, são apresentados inicialmente os resultados da etapa de estruturação do problema de design, sintetizando os requisitos do projeto e, em seguida, são apresentadas as etapas de ideação e prototipação da gamificação, incluindo as suas dimensões estruturais, analógicas e digitais. 


\subsection{Estruturação do problema de design: diagnóstico e requisitos}

O uso das técnicas de pesquisa, como entrevistas, pesquisas dos documentos pedagógicos da escola, observações e análise motivacional a partir do Octalysis, contribuíram para a construção dos requisitos formais da solução. Durante toda etapa de pesquisa, os dados coletados foram documentados em mapas mentais, como ilustrado pela Figura 3.

No centro do mapa exemplificado localiza-se o objetivo geral do projeto e, a partir dele, são traçadas as problemáticas observadas e relatadas. Em seguida, são descritas observações do contexto que justificam tais problemáticas sob as diferentes perspectivas e, por fim, são evidenciadas as sugestões de solução. Com os requisitos devidamente delineados, tornou-se possível a geração de alternativas mais palpáveis e adequadas ao contexto.

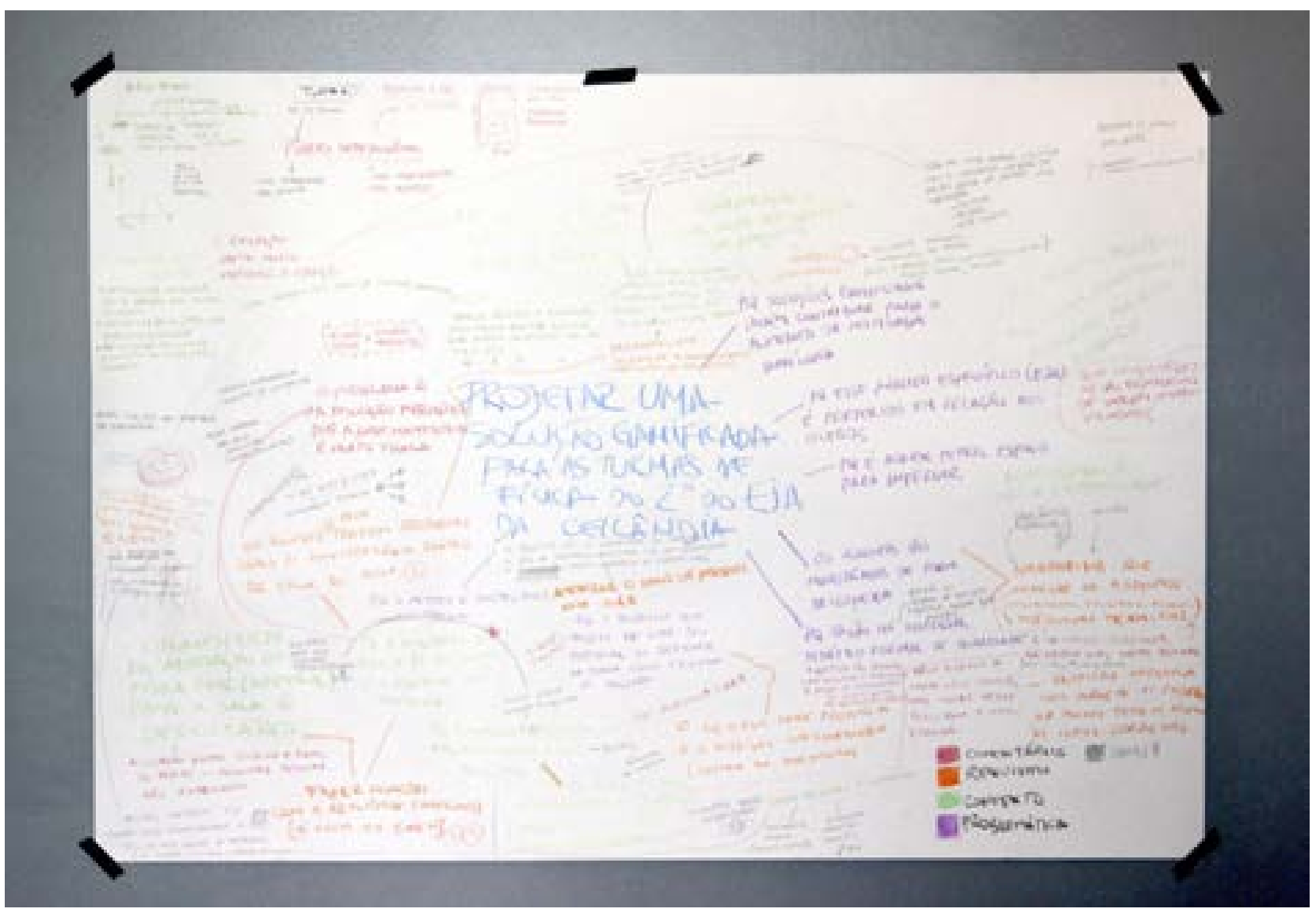

Figura 3: Mapa mental construído durante a etapa de estruturação do problema de design

Os requisitos foram organizados em:

- Tornar o conteúdo mais claro por meio de contextualização com a realidade;

- Fazer ligação com a realidade a partir de gatilhos;

- Fazer conexão entre os assuntos por meio de uma narrativa;

- Aproveitar o tempo das aulas e não passar tarefas para serem feitas em casa garantindo que as dúvidas sejam sanadas;

- Utilizar mídias digitais de forma acessível

- Alavancar o conhecimento prático pessoal dos alunos;

- Alunos e professor podem trazer problemas reais para solucionarem em sala de aula;

- Passar sensação de controle sobre as atividades e conteúdos aprendidos por meio de feedbacks instantâneos:

- Tornar a solução engajadora para todas as turmas e sua diversidade de alunos;

- Garantir o uso de mecânicas de jogos que estejam dentro do âmbito dos motivadores: Aversão à Perda, Significado Épico e Realização, identificados como centrais no grupo focal;

- Repensar a utilização do material didático, criando um roteiro de estudos com conteúdos autorais do professor, para que um dia substituam as apostilas.

Os mapas permitiram registrar as principais representações de alunos, professor e projetistas ao longo da condução do diagnóstico. Assim, foram evidenciados os suportes utilizados para a realização das atividades, os principais problemas da situação investigada, as estratégias adotadas para contorna-las, os seus efeitos nas pessoas envolvidas, assim como as motivações de cada um dos envolvidos.

Ainda, em vez de se buscar uma simplificação do problema pela abstração da representação adotada para o contexto, procurou-se evidenciar as suas inconsistências e dissimilitudes, levando para a fase de ideação de uma nova organização da atividade a responsabilidade pela negociação entre as diferentes representações e estratégias identificadas. Com isso, espera-se que as novas propostas sejam mais adequadas ao contexto, retirando dos alunos a responsabilidade pelo ajuste entre o que foi planejado e as dificuldades apresentadas pela realidade cotidiana da escola.

\subsection{Fase de Ideação}

o processo de ideação foi construído ao longo de todo o projeto, e pode-se entender que houve três ciclos de iteração: uma geração livre e exploratória, sem muita preocupação em adequação ao contexto, uma segunda iteração contextual, mais aderente após os primeiros resultados das pesquisas e, por fim, uma iteração cocriativa, dividida em vários encontros que contaram com participação ativa do professor da disciplina. Desse modo, para cada requisito levantado na pesquisa de estruturação foi designado um ou mais atributos capazes de contemplá-la, como pode ser observado no Quadro 1.

A partir das propostas selecionadas, pode-se constatar que a solução aconteceu em três campos: estrutural, analógico e digital. Por se tratar de um sistema complexo que leva em consideração as variáveis da aprendizagem dos alunos do CED 6, a gamificação inverteu a lógica pedagógica, manifestou-se em artefatos analógicos e incluiu recursos digitais na aprendizagem de física.

Quadro 1: Síntese de requisitos e atributos relacionados na fase de ideação do projeto. 


\section{Requisitos}

Clareza: (1) Tornar o conteúdo mais claro por meio de contextualização com a realidade; (2) Fa(3) Fazer conexão entre os assuntos por meio de (3) Fazer conexä

Aproveitar o tempo das aulas e não passar tarefas para serem feitas em casa, garantindo que as dúvidas sejam sanadas;

Utilizar mídias digitais de forma acessível a todos:

Descentralização: (1) Alavancar o conhecimento prático pessoal dos alunos; (2) Alunos e professor podem trazer problemas reais para solucionarem dentro de sala de aula;

Passar sensação de controle sobre as atividades e conteúdos aprendidos através de feedbacks instantâneos:

Tornar a solução engajadora para todas as turmas e sua diversidade de alunos;

Garantir o uso de mecânicas de jogos que estejam dentro do âmbito dos motivadores positivos para reduzir o motivador de Aversão à Perda: (1) Significado Epico, (2) Rea mento da Criatividade;

Repensar a utilização do material didático, criar um roterio de estudos com conté́ dos autorais do professor, para que um dia substituam as apostilas;

\section{Atributos}

(1) Usar abordagem inspirada em Problem Based Learning (PBL); (2) Usar exemplos reais e cotidiahivir os assuntos em ciclos de conhecimento mais complexo de aplicável (Máquinas Térmica nais complexo aplicável (Máquinas Termicas, os conteúdos teóricos a partir disso (a exemplo, Transformação Isobárica):

Propor uma nova estrutura de aula, aproveitando melhor os 40 minutos de aula, de uma maneira que conecte os assuntos de todas as aulas à narrativa de Máquinas Térmicas: $1^{\circ}$ ) Recapitulação; $2^{\circ}$ ) Situação Problema; $3^{\circ}$ ) Explicação e Resolução do Exercício; $4^{\circ}$ ) Check out;

Criar grupos de whatsapp para cada turma onde os exercícios possam ser passados para ganhar tempo de aula. Dividir a sala em grupos de, no mínimo, 4 (quatro) alunos, de tal forma que, pelo menos 1 (um) aluno tenha celular

(1) Criar um momento para que os alunos discuam entre si e possam ensinar os conteúdos com suas palavras: (2) Abordagem inspirada em PBL

Implementar o uso de uma cartilha de vistos,

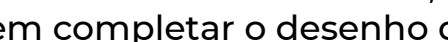
Geladeira, através de adesivos colecionáveis, conforme aprendam sobre cada componente dela, demonstrando o avanço feito a cada aula;

\section{Utilizar as características de Dynamic Difficulty} Adjustment (DDA) em avaliações no estilo de prova;

Usar mecânica Narrativa (1), Barra de Progresso (2), Troféus (2), Desbloqueio de Marco (3), Feedbakk Intantaneo (3), entre outras, de outros motivadores como Missões em Grupo, Efeito Oráculo Conjuntos Colecionáveis:

Fazer um blog exclusivo para a matéria de acesso fáci permita downloads e seja amigável para o professor para os alunos. nos na construção de exercícios de fixação; (3)

\section{Solução no âmbito estrutural}

A primeira mudança no método de aprendizagem proposta consiste na criação de um sistema que permita evocar um conhecimento prático pessoal dos alunos, fugindo da abstração dos números para criar gatilhos de conhecimentos fáceis de serem lembrados. Assim, foi proposta a doção de uma narrativa sobre alguma máquina térmica já conhecida pelo grupo, optando-se pelo uso da geladeira, considerada um eletrodoméstico conhecido. Entretanto, para fazê-lo foi necessária a inversão dos conteúdos didáticos, que antes começavam com os conceitos mais abstratos e básicos, para chegarem na complexidade das máquinas térmicas somente no final do período letivo. Portanto, criou-se a narrativa sobre o funcionamento da geladeira para que, a partir dela, os alunos possam estudar os seus componentes que se desdobram em conteúdos mais teóricos e abstratos, como pode ser visto na Figura 4.

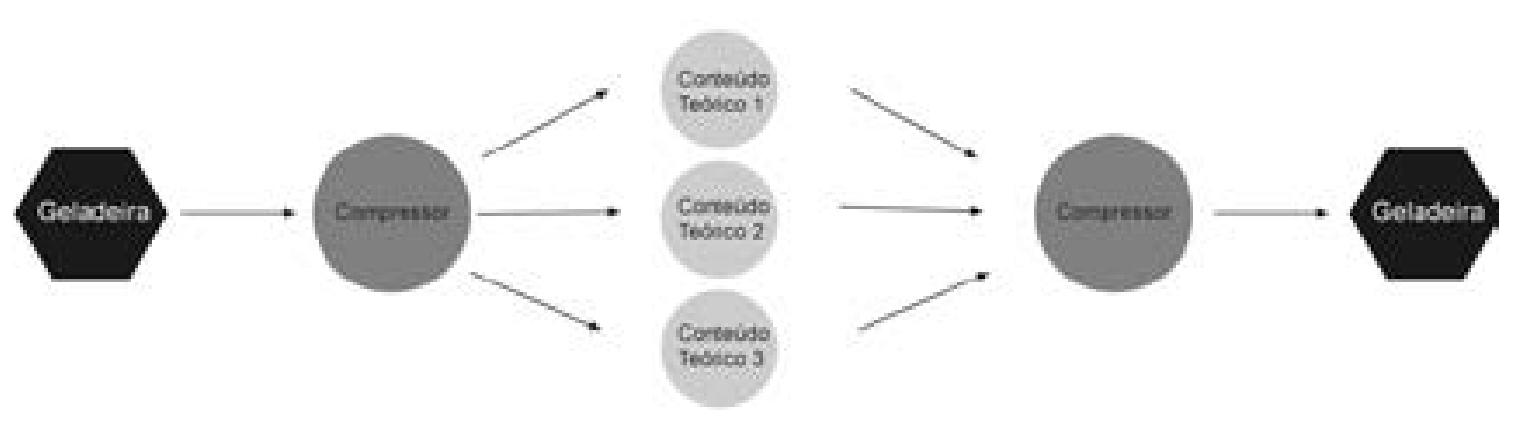

Figura 4: Ciclo de aprendizagem a partir da máquina térmica (geladeira) seguindo para componente (compressor) divergindo para conceitos teóricos.

Partindo da abordagem educacional baseada em problemas (PBL), o fluxo de funcionamento em sala de aula também foi invertido. Inicialmente, havia um longo momento de cópia no quadro, seguido de explicação expositiva e, por fim, execução de exercícios. Eles foram revistos para um momento de (a) recapitulação do conteúdo visto nas aulas anteriores, para que em seguida fosse passada uma (b) situação problema, que os alunos devem tentar responder evocando a bagagem de conteúdos que possuem, para então, pararem para um momento de (c) explicação do professor. Por fim, é realizado um (d) check out que é o momento em que os alunos recebem o feedback de seu progresso na aprendizagem da geladeira. Entende-se que, desta maneira, o professor passa a adotar a postura de facilitador do conhecimento, não mais centralizando o processo de aprendizagem, aumentando a autonomia dos alunos (FREIRE, 2011), uma prática considerada ainda mais pertinente em contextos informacionais contemporâneos (FILATRO, 2010). A nova configuração pode ser vista na Figura 5.

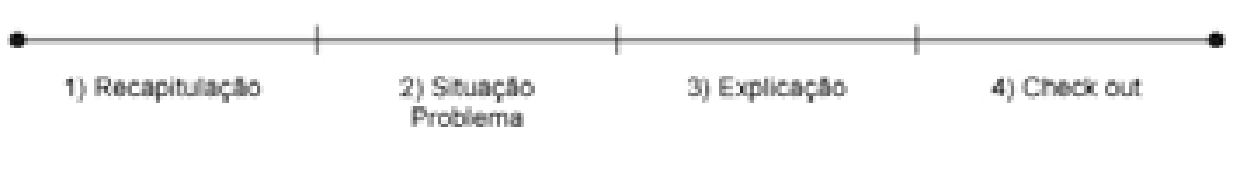

Figura 5: Fluxo proposto para a organização das aulas. 
É importante ressaltar que na etapa de situação problema, o professor teve a liberdade de explorar três tipos de circunstância: experimentos em sala-de-aula, no qual o professor pode evidenciar uma aplicação real da física no dia-a-dia; cartas de exercícios, designadas a conter a situação problema; e cartões de webquest designados à avaliação para conclusão do conteúdo teórico contido no componente da geladeira em questão. As cartas de exercícios e os cartões de webquest são descritos posteriormente no presente relato.

\section{Solução no âmbito analógico}

Para fins de tangibilidade entre a narrativa e os processos de sala de aula como, por exemplo, explicação, exercícios e avaliação de notas, foram criados artefatos impressos que funcionam como suportes para a interação dos alunos. Assim, o primeiro artefato foi um banner de direcionamento do conteúdo, no qual os alunos podem ver a anatomia da geladeira, bem como, quais conteúdos teóricos estão associados em cada componente visando a sua autonomia e orientação ao longo da disciplina (Figura 6).

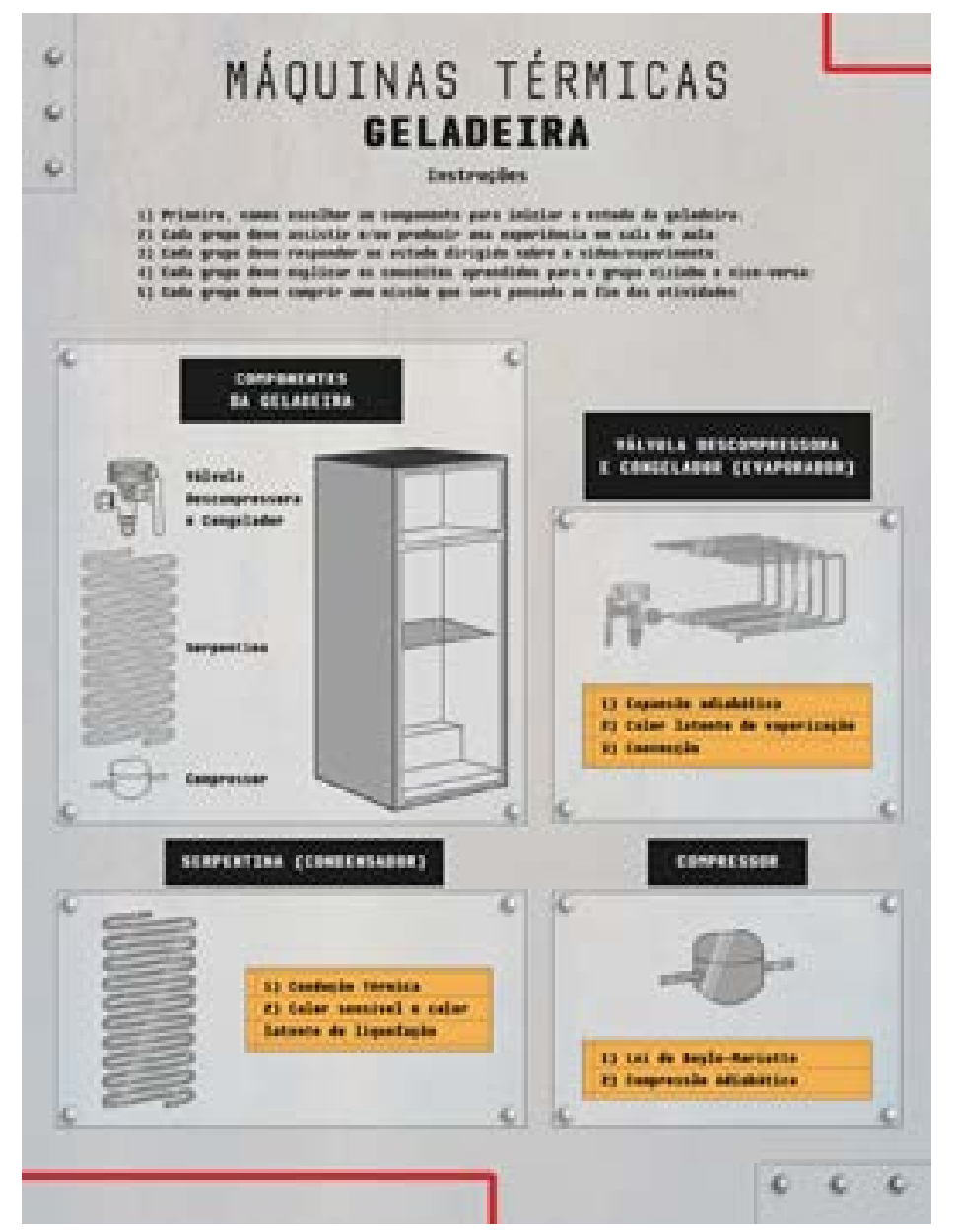

Figura 6: Banner de direcionamento do conteúdo baseado na anatomia da geladeira.
O banner consiste na porta de entrada dos alunos para a gamificação. Portanto, para o melhor entendimento e leitura, foram concebidas ilustrações da geladeira e seus componentes, seguindo a identidade visual proposta para o projeto. Ele possui 60 centímetros de largura e 80 centímetros de altura, podendo ser impresso em papel ou vinil. O banner comporta, também, instruções de como se traduzirá o ciclo de aprendizagem a partir da narrativa dentro do processo de sala de aula.

Visando o acompanhamento e controle de qual componente está sendo estudado em cada momento, foi criada uma cartilha de adesivos com a mesma anatomia da geladeira. Dessa forma, os alunos recebiam recompensas (os adesivos) ao completarem o ciclo referente àquele componente específico. Esta cartilha, juntamente com os adesivos, estruturam a mecânica de conjuntos colecionáveis e são uma forma de reduzir o motivador de aversão à perda, dando ao aluno a sensação de controle sobre sua própria trajetória. $\mathrm{O}$ artefato completo, contemplando cartilha e um adesivo pode ser visto na Figura 7.

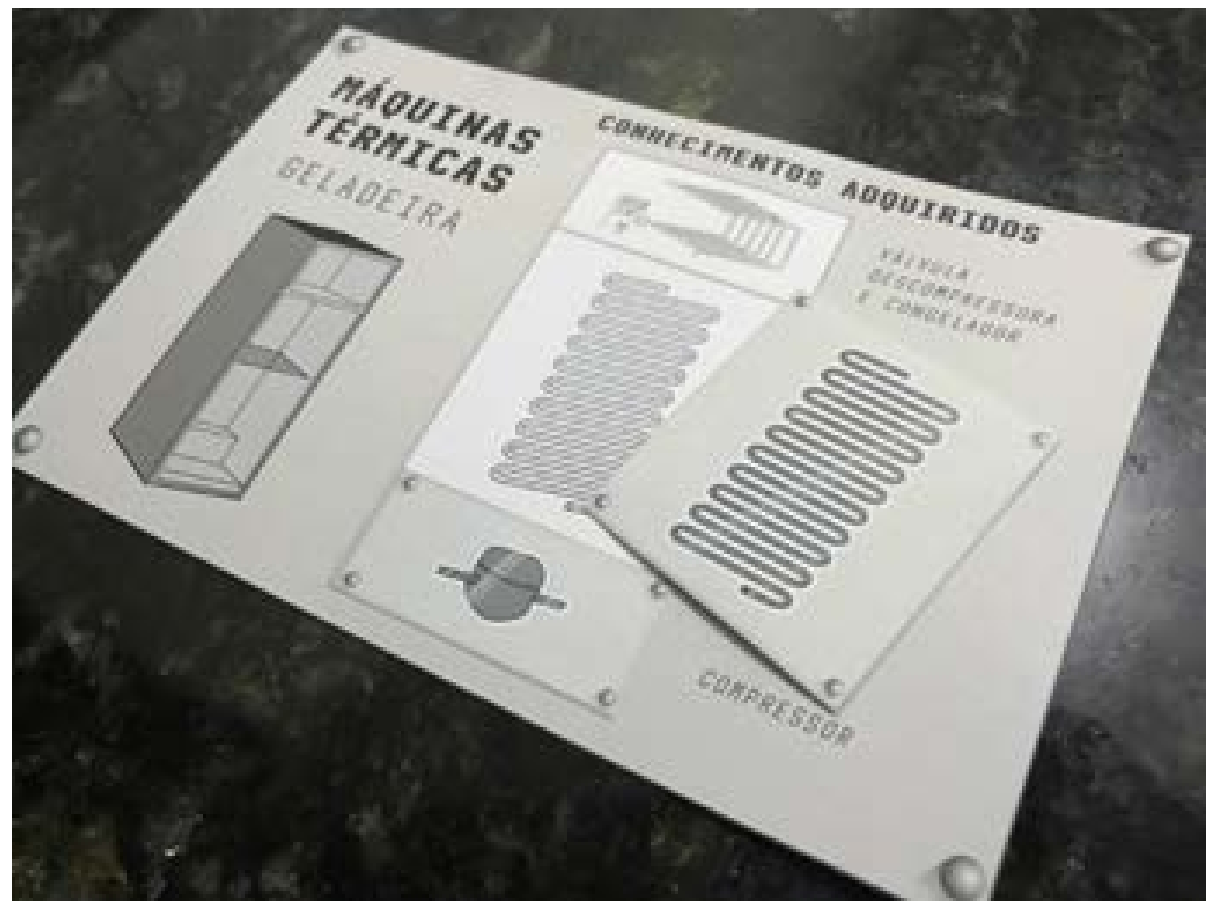

Figura 7: Cartilha de adesivos ilustrando os componentes da geladeira.

\section{Solução no âmbito digital}

O uso do campo digital na solução surgiu para preencher as lacunas entre a educação em sala de aula e a velocidade do pensamento digital dos alunos. A solução se deu em dois ambientes virtuais: um blog criado para o projeto e em grupos de WhatsApp. O blog foi criado usando a ferramenta Wix. A escolha de uso da ferramenta ocorreu porque foi considerada de fácil atualização, o que facilita a alimentação de conteúdos por parte do professor. Além disso, a centralização do conhecimento e dos exercícios em um blog deve facilitar o acesso dos alunos aos conteúdos.

O blog foi dividido por turmas, sendo que cada sessão contém uma barra 
de progresso da turma. Esta ferramenta, intitulada "painel da evolução", contém o componente estudado durante aquele período e o nível de progressão dos alunos nas atividades referentes àquele conhecimento. O feedback para controle dos usuários é determinado por uma luz que acende quando as aulas daquele conhecimento são realizadas. $O$ painel pode ser visto na Figura 8.
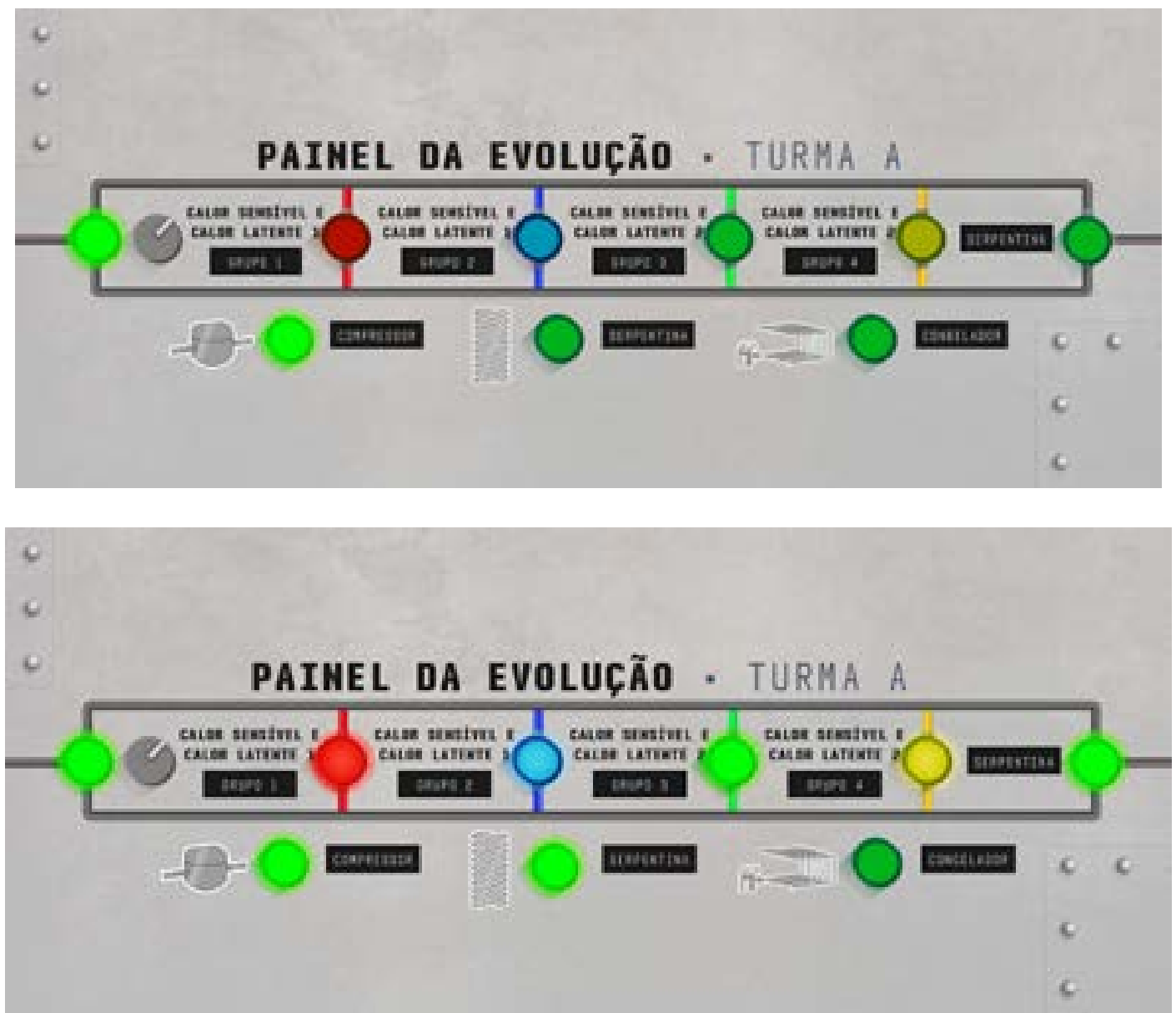

Figura 8: Dois exemplos da barra de progresso das turmas indicando os conteúdos do compressor. $\mathrm{Na}$ parte de cima pode ser visto o painel que indica que a turma A não completou as atividades. Na parte de baixo, o painel indica que a turma completou as atividades e que o próximo componente é a serpentina.

O segundo ambiente utilizado foi o aplicativo WhatsApp devido ao uso frequente por parte dos alunos, identificado na etapa de diagnóstico da pesquisa. Os grupos se tornaram um importante canal de comunicação entre o professor e a turma, pois as cartas de exercícios e os cartões de webquests são transmitidos por esse meio. Um exemplo de carta de exercício pode ser visto na Figura 9 e de webquest pode ser visto na Figura 10. Ambos os cartões são produzidos por meio de imagens no formato .jpeg enviadas dentro dos grupos de WhatsApp. Ambas contribuem para o avanço na barra de progresso da turma para que, desta forma, tanto o professor quanto os alunos saibam qual conhecimento está sendo aprendido, o que mitiga ainda mais a aversão à perda constatada na etapa de pesquisa.

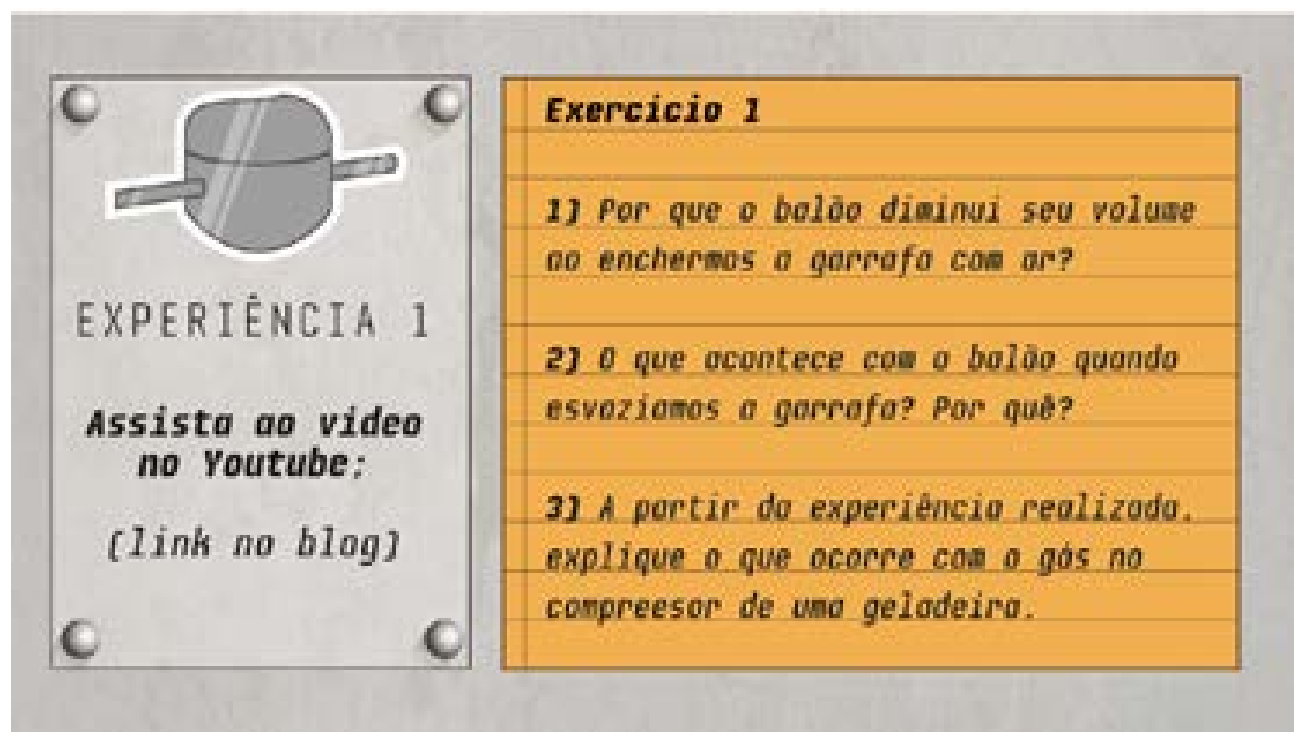

Figura 9: Exemplo de Carta de Exercícios com instruções sobre como os alunos podem proceder.

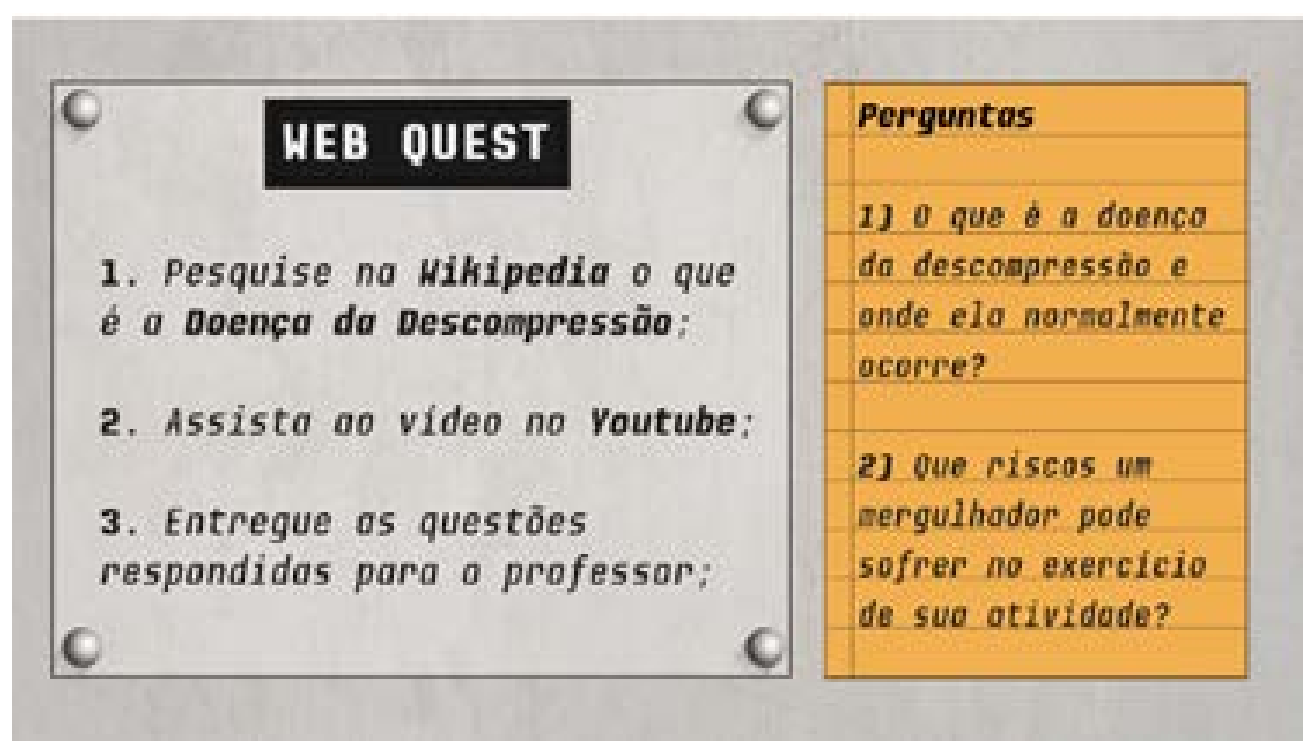

Figura 10: Exemplo de Cartão de webquest com instruções sobre como realizar a avaliação.

Os exercícios que são aplicados por meio das cartas e de webquest também foram disponibilizados no blog por meio de postagens. A plataforma permite também a visualização de vídeos do Youtube diretamente no blog, o que facilita o uso e a sua adoção em sala de aula. Outras funcionalidades consideradas relevantes não foram incorporadas na versão adotada para a fase de testes, como, por exemplo, a possibilidade de autenticação para conteúdos personalizados, ferramentas de postagens de comentários e disponibilidade de downloads dos conteúdos. 


\section{Reflexões acerca da intervenção}

O desenvolvimento da pesquisa aponta para uma abordagem considerada atual do processo de design, em que o objeto de estudo não é necessariamente tangível embora possa abarcá-lo, mas sobretudo consiste na articulação das interações das pessoas mediadas por artefatos tecnológicos dentro de um determinado sistema, como no design de interação ou design de serviços. Entende-se que problemas reais inseridos em contextos complexos convidam designers a abandonarem o paradigma vigente de tangibilidade do design e a buscarem uma compreensão holística do funcionamento do sistema. Embora seja um convite desafiador, a experiência dos autores obtida com o presente estudo reforça a validade de aceitá-lo, como sugerem Cardoso (2012), Vassão (2010), ou mesmo Alexander (1971), entre outros autores a abordarem a dimensão da complexidade na atividade projetual. Do mesmo modo, a perspectiva adotada no desenvolvimento do estudo é consoante com as afirmações dos autores sobre a maior aderência à realidade proporcionada por projetos desenvolvidos em campo, de maneira indutiva, com aprofundamento em contexto.

Durante o seu desenvolvimento, as etapas iniciais de imersões do estudo foram mais longas e detalhadas, demonstrando a importância dedicada à compreensão profunda do contexto, como sugere a Ergonomia. Apesar disso, algumas situações inusitadas podem ser percebidas na fase de geração livre de alternativas, nas quais, para fins de fomento da criatividade do processo, o contexto não foi levado em consideração em determinados momentos, fazendo com que diversas possíveis soluções fossem concebidas. Assim, foi possível empregar a estratégia de alternância entre pensamentos divergentes e convergentes do design, separando momentos de julgamento dos momentos de ideação livre, potencializando ambos.

Um exemplo envolve a criação de uma narrativa espacial, com possibilidades de gamificação em variados elementos: a atribuição de papéis específicos a cada indivíduo segundo suas aptidões profissionais, a presença de mecânicas de bens virtuais, entre outras possibilidades. Sob algumas perspectivas de projeto, a ideia tinha potencial de outras possibilidades. Sob algumas perspectivas de projeto, a ideia tinha potencial de
sucesso, contudo, ao confrontá-la com a realidade, foi verificada a falta de aderência ao contexto: mais da metade do público-alvo é adulto, com pouca aceitação de contexto lúdicos; a mecânica de bens virtuais não é a mais relevante para eles, uma vez que visa o estímulo de pertencimento e posse, que não é o principal motivador detectado. Percebese, portanto, que o projeto poderia ter desviado seu curso de maneira negativa caso não houvesse a centralidade no usuário e a compreensão do seu contexto, suportes, constrangimentos, motivações e metas.

Com isso, entende-se que o diagnóstico ergonômico, voltado para a perspectiva dos usuários, é de suma importância, sobretudo em contextos diversificados, dinâmicos e complexos. No início da década de 70, quando Victor Papanek (2000) publicou seu livro Design for the real world (Design para o mundo real), o autor incomodou a comunidade ao expor a noção da inobservância da realidade, o que até hoje provoca a muitos projetistas. A transformação da realidade, especialmente uma complexa, como se encontram as sociedades atuais, exige a interação de diversos agentes. Por esse motivo, é importante que o processo de design aborde as diversas partes de um sistema, aliando, confrontando e acomodando variados pontos de vista, suas divergências e contradições, de modo a se obter um entendimento aderente.
Apesar disso, considera-se pouco provável que a solução proposta nesse estudo represente um avanço na Educação pública de Jovens e Adultos do Distrito Federal isoladamente. Embora o resultado atingido tenha envolvido o melhor esforço dos pesquisadores e designers responsáveis, deve-se reconhecer que ainda há diversos desafios que extrapolam os limites da sala de aula. Dentro do contexto nacional, considerado diverso e heterogêneo, esse impacto pode ser estimado como muito pequeno. Contudo, também se considera questionável a viabilidade de qualquer projeto que pretenda transformar uma realidade diversa como essa em um curto espaço de tempo.

Apesar do escopo do presente relato não abordar o impacto da intervenção, que pode ser mais bem compreendido em Lopes et al (2019), o processo que envolveu professor e alunos na construção de uma visão crítica sobre o papel da disciplina em suas vidas gerou indicadores preliminares que sugerem um aumento de engajamento dos alunos. O número de desistentes por turma, os horários de saída e chegada, assim como o envolvimento com as atividades propostas, demonstram o potencial da nova estratégia de aprendizagem concebida. Não obstante, o que se espera discutir são as peculiaridades do próprio percurso interventivo, gerando reflexões sobre a adoção da abordagem ergonômica associada ao processo de design para se compreender e transformar uma realidade local.

Durante a fase de imersão e diagnóstico, fica evidente a contribuição da ergonomia para a formulação do diagnóstico do contexto. A partir do estudo realizado, entende-se que a flexibilidade procedimental proposta pela abordagem ergonômica é determinante para se atingir a aderência ao contexto investigado. A alternância entre as observações globais e participativas, análises de documentos formais e informais relacionados, assim como das entrevistas semiestruturadas e grupos focais permitiu uma imersão na perspectiva de alunos e do corpo pedagógico da escola, permitindo questionamentos mais profundos acerca das diferentes visões levantadas.

Além disso, a combinação entre os procedimentos previstos pela abordagem ergonômica e a proposta de levantamento de motivações da Octalysis permitiu uma discussão mais objetiva acerca dos diferentes valores associados às motivações dos alunos para frequentar o ambiente de EJA. Esse entendimento foi fundamental para que fossem concebidas estratégias mais significativas de envolvimento dos alunos.

É ainda muito cedo para que se possa formalizar a efetividade do estudo realizado a longo prazo, trabalho ainda em andamento pela pesquisa vinculada. É importante, contudo, ressaltar, enquanto resultado evidente da presente pesquisa, que o públicoalvo delimitado carece de um novo projeto de educação focado nas suas autênticas necessidades. O que se percebe, ao observar a realidade de EJA, é que se trata de uma replicação do formato de ensino tradicional que não leva em conta as suas distinções. Sendo ainda mais realista, o próprio modelo tradicional já vem há alguns anos sofrendo muitas críticas, sendo considerado inadequado ao contexto contemporâneo.

Finalmente, se faz relevante também abordar o papel dos professores. O presente relato é fruto de uma inquietação do professor da escola investigada, sem o qual esse estudo certamente não teria tocado a dimensão da realidade. Seu engajamento, motivação e envolvimento foram fundamentais para o sucesso da implementação planejada. Esse é um custo muitas vezes não contabilizado em processos de natureza 
interventiva, que se desdobra em fracassos nas etapas de replicação justamente po essa desconsideração. Assim, também se avalia necessário ressaltar a importância da existência de cursos de formação de professores específicos para a modalidade de EJA, visando atenuar esses efeitos.

\section{Considerações finais}

O presente relato conclui-se com uma análise qualitativa preliminar acerca da proposta de intervenção que puderam ser percebidos em uma aplicação inicial. No início do mês de novembro de 2017, a proposta foi testada em sala de aula a fim de verificar a sua aceitação pelo público-alvo. A impressão inicial registrada pelo professor é positiva: alunos que não costumavam participar tanto da aula passaram a se interessar mais, e o uso dos experimentos despertou a curiosidade de muitos deles. É importante mencionar uma observação do professor a respeito do desafio dessa abordagem quanto a sua vulnerabilidade a interrupções, pois o uso da narrativa da geladeira necessita de continuidade até que termine, de tal forma que intervalos no ciclo de aprendizagem são prejudiciais. Por se passar em uma instituição de ensino pública, interrupções em diversos campos atrapalharam a apreensão da narrativa na sua aplicação e, por consequência, do conhecimento gerado a partir dela.

Outra consequência derivada da abordagem empregada é a facilidade de atualização do projeto. A solução proposta enquanto sistema permite que os produtos resultantes de uma turma possam gerar insumos para material didático de turmas posteriores, atenuando um pouco a carga de trabalho dos professores ao longo do tempo. Finalmente, o engajamento das pessoas envolvidas é também uma qualidade esperada dessa abordagem na medida em que torna a tarefa do usuário mais clara, prazerosa e motivadora.

Portanto, conclui-se que a gamificação associada ao processo de design e à abordagem ergonômica têm elevado potencial para serem empregados como ferramentas de interação social capaz de conectar indivíduos. A escolha pela gamificação de modo complementar ao diagnóstico ergonômico, de natureza aberta e real, adiciona ao projeto a qualidade de poder ser aderente ao contexto de trabalho, diferente de soluções mais rígidas e pouco adaptáveis. Para tanto, a compreensão das representações de todos os atores envolvidos, assim como de suas principais estratégias e dificuldades cotidianas são relevantes para o diagnóstico. A partir deste entendimento, a nova organização da atividade, concebida pela perspectiva do design de interação, assim como os seus suportes físicos e analógicos, se tornam mais pertinentes e significativos.

\section{REFERÊNCIAS}

ABRAHAO, Julia et al. Introdução a ergonomia: da prática a teoria. Brasil: Edgard Blucher, 2009. $240 \mathrm{p}$.

ALEXANDER, C. Notes on the Synthesis of Form. Cambridge, Massachusetts, London: Harvard University Press, 1971.

\section{BONSIEPE, G. Design, cultura e sociedade. São Paulo: Blucher, 2011.}

BONSIEPE, G. Design do material ao digital. Florianópolis: Lab Bras Design, 1997.

BRASIL. Instituto Nacional de Estudos e Pesquisas Educacionais Anísio Teixeira Inep divulga dados inéditos sobre fluxo escolar na educação básica. 2017. Disponível em: $\quad$ <http://portal.inep.gov.br/artigo/-lasset_publisher/B4AQV9zFY7Bv/content/inepdivulga-dados-ineditos-sobre-fluxo-escolar-na-educacao-basica/21206>. Acesso em: 9 ago. 2017.

CAÑAS, J.J., ANTOLÍ, A. \& QUESADA, J. F. The role of working memory on measuring mental models of physical systems. Psicológica, 22, 25-42, 2001.

CARDOSO, R. Design para mundo complexo. São Paulo: Cosac Naify, 2012.

CHEN, J. Flow in games. 2006. Dissertação (Mestrado) - University of Southern California. Los Angeles, 2006.

CHOU, Yu-kai. Gamification \& behavioral design. 2015. Disponível em: <http:// yukaichou.com/gamification-examples/octalysis-complete-gamification-framework/s. Acesso em: 23 out. 2017.

CSIKSZENTMIHALYI, M. Flow: the psychology of optimal experience. Harper Perennial, 1990.

DESIGN COUNCIL (United Kingdom). Designers across disciplines share strikingly similar approaches to the creative process, which we've mapped out as 'the Double Diamond'. c2017. Disponível em: <http://www.designcouncil.org.uk/newsopinion/design-process-what-double-diamond>. Acesso em: 15 set. 2017.

FADEL, L. M.; ULBRICHT, V. R.; BATISTA, C. R.; VANZIN, T. (orgs). Gamificação na educação. São Paulo: Pimenta Cultural, $2014300 p$.

FILATRO, Andrea. Design instrucional contextualizado. São Paulo: Senac, 2010.

FREIRE, Paulo. Pedagogia da autonomia: saberes necessários à prática educativa. São Paulo: Paz e Terra, 2011.

GUÉRIN, F.; LAVILLE, A.; DANIELLOU, F.; DURAFFOURG, J. e KERGUELEN, A. Compreender o trabalho para transformá-lo: A prática da Ergonomia. Tradução de: $L$. Sznelwar et al. São Paulo: Edgard Blücher LTDA, 2001.

HMELO-SILVER, Cindy E.; BARROWS, Howard S. Goals and Strategies of a Problembased Learning Facilitator. Interdisciplinary Journal Of Problem-based Learning, [s.I.], v. 
1, n. 1, p.1-39, 22 maio 2006.

KAPP, Karl M.; BLAIR, Lucas; MESCH, Rich. The gamification of learning and instruction fieldbook: ideas into practice. United States: Pfeiffer, 2013. 480 p.

LOPES, F. G. S.; SILVA, T. B. P.; DOMINGOS FILHO, C. A.; VALE, M. E. B. Design de estratégia de ensino-aprendizagem para o estudo de máquinas térmicas. Estudos em design, v. 27, p. 108-133, 2019.

LOWDERMILK, Travis. User-Centered Design: A developer's guide to building user-friendly applications. 2013. $184 \mathrm{p}$

MATTOS, Tiago. Vai lá e faz: como empreender na era digital e tirar ideias do papel. 2017. Disponível em: <http://assets.perestroika.com.br.s3.amazonaws.com/vlef/vlef.pdf>. Acesso em: 18 julho 2017.

NEWELL, A.; SIMON, H. A. Human Problem Solving. Prentice Hall: Englewood Cliffs, NJ, 1972.

PAPANEK, $V$. Design for the real world: human ecology and social change. Chicago: Academy Chicago Publishers, 2000.

PRENSKY, Marc. Digital game-based learning. United States: Paragon House, 2001. $464 \mathrm{p}$.

SAFFER, Dan. Designing Gestural Interfaces. 2010. 270 p.

SILVA, T. B. P. A cognição no processo de design. Revista Brasileira de Design da Informação - Infodesign, v. 12, n. 3, p. 318 - 335. São Paulo: 2015.

SILVA, T. B. P. Projetando a Navegabilidade: Ergonomia Cognitiva e Design de Interação In: III Simpósio Nacional de Tecnologia e Sociedade - Desafios para a Transformação Social. Curitiba: 2009.

SILVA, T. B. P. Um campo epistemológico para o Design. Revista de Design, Tecnologia e Sociedade, v. 2, p. 23-41, 2016.

SILVINO, A. M. D.; ABRAHÃO, J. I. Navegabilidade e inclusão digital: navegabilidade e competência. Revista de Administração de Empresas, RAE-Eletrônica. 2(2), 2003. Disponível em: < http://www.rae.com.br>. Acesso em: 05 out. 2004.

VASSÃO, C. A. Metadesign: ferramentas, estratégias e ética para a complexidade. São Paulo: Blucher, 2010.

\section{Agradecimentos}

Agradecemos a oportunidade de acesso à educação pública e gratuita de qualidade, com a qual esperamos contribuir com pesquisas presentes e futuras. Por mais investimentos em educação no Brasil. 